\title{
Analysis of ordering pattern and cost effectiveness of thyroid function tests for diagnosing thyroid diseases.
}

\footnotetext{
1. MBBS, M.Phil (Chemical Pathology) Assistant Professor Chemical Pathology Pakistan Institute of Medical Sciences, Islamabad.

2. MBBS, M.Phil (Hematology) Assistant Professor Hematology Khyber Medical College.

3. MBBS

House Officer

Pakistan Institute of Medical Sciences.

4. MBBS

House Officer

Pakistan Institute of Medical Sciences

5. MBBS

Medical Officer

Pakistan Institute of Medical

Sciences.
}

Correspondence Address:

Dr. Muhammad Ihtesham Khan Assistant Professor Hematology

Khyber Medical College.

ihteshamkhan9@yahoo.com

Article received on:

17/02/2020

Accepted for publication:

$13 / 04 / 2020$
Saman Waqar', Muhammad Ihtesham Khan ${ }^{2}$, Rahy Farooq ${ }^{3}$, Mahira Mobeen ${ }^{4}$, Rafi Raza Ahmad ${ }^{5}$

ABSTRACT... Objectives: To determine the ordering pattern and cost effective use of thyroid function tests for diagnosing thyroid diseases. Study Design: Retrospective Observational study. Setting: Department of Pathology, Pakistan Institute of Medical Sciences, Islamabad. Period: 1st December 2016 to 31st February 2017. Material \& Methods: The data regarding the number of entitled patients and the cost of each of T3, T4 and TSH was determined. Also the number of cases where the thyroid profile was normal were determined and analysis was made about whether was there any need to prescribe full profile. Mean and standard were used for quantitative variables and frequency and percentages were applied for qualitative data. About 1491 patients were included in the study. Results: Mean age of the study sample was $25 \pm$ 6.5 years (range: 1 years to 80 years). There were $579(39 \%)$ males and $912(61 \%)$ females. About $700(46.9 \%)$ patients were entitled. Majority of the cases were from medicine and gynae obstetrics units of the hospital i.e $644(43.2 \%)$ and $549(36.8 \%)$ cases respectively. In about 838 $(56.2 \%)$ cases, the thyroid function tests were normal. Conclusion: There is a huge financial burden on patients as well on the hospital regarding performing thyroid function tests in clinical setup. There is a need to spread awareness among junior doctors to ensure judicious advising of the thyroid function tests in patients especially in cases coming from low socioeconomic class and in cases of entitled patients, whose burden is from the government funds.

Key words: $\quad$ Thyroid Function Tests, Thyroid Stimulating Hormone, T3, T4.

Article Citation: Waqar S, Khan MI, Farooq R, Mobeen M, Ahmad RR. Analysis of ordering pattern and cost effectiveness of thyroid function tests for diagnosing thyroid diseases. Professional Med J 2020; 27(11):2394-2398. https://doi.org/10.29309/TPMJ/2020.27.11.4579

\section{INTRODUCTION}

Thyroid function, abbreviated as TFT, is a laboratory test that is done in order to determine the thyroid functioning. ${ }^{1}$ The thyroid may be either overactive (hyperthyroidism) or underactive (hypothyroidism). ${ }^{1}$ The appropriate diagnosis and treatment of thyroid disorders is important as the hyper function sing or hypo functioning of the gland has serious effects on the body. ${ }^{2,3}$

A panel of three hormones are assessed in the TFTs. This includes thyroid stimulating hormone (TSH), tri iodo threonine (T3), and thyroxin (T4). ${ }^{1}$ However, among these three tests, the TSH is known to be most important as it is more sensitive test for detecting thyroid diseases. ${ }^{1} \mathrm{TSH}$ has a stimulatory effect on the thyroid. Due to it its increased sensitivity, it is regarded as a more reliable test for screening thyroid diseases in popluation. ${ }^{1}$

The thyroid disorders are amongst one of the commonest endocrine disorders all over the world. ${ }^{1}$ The worldwide incidence of thyroid disorders is about 259 cases per 100000 individuals per year. ${ }^{1}$ The prevalence of thyroid disorders all over the world is $3.8 \% .^{1}$ The literature suggests that the general PR actioners and junior doctors are advising thyroid functions at a higher rate and that is why the number of thyroid tests per year is increasing. . $^{4,5}$ Literature also suggests that the number of thyroid requests is much more higher than the actual prevalence of thyroid disorders in population itself. ${ }^{6}$

All over the world, there is an approach to design 
the healthcare budget in such a way that the diagnostic accuracy is not effected yet funds are used efficiently. In the United Kingdom, about ten thousand thyroid function tests are ordered per year. ${ }^{1}$ This costs about thirty million pounds to the British government every year. ${ }^{1}$ It is required that the laboratory tests would be done a sensible way so that the funds are not wasted on them. This is especially true for developing countries where people have poor socioeconomic lifestyle.

Different approaches are used by researchers to decrease the number of inappropriate thyroid function tests. ${ }^{1}$ One of the method used was by reporting to the consultants the number of thyroid tests performed at the end of each year so that there is a feedback system developed to monitor the control over the number of tests. ${ }^{1}$ The other method was to display the cost of these tests before the doctor advises them to the patients. ${ }^{7}$ This method was found effective in reducing the number of thyroid tests. ${ }^{7}$ These efforts were focused on the junior doctors, physicians and nurses. $^{1}$

This study was done to analyze the cost effectiveness of the TFTs in diagnosing the thyroid diseases. This will assist in making a scheme to lower the economic burden of these tests on patients as well as the patients.

\section{MATERIAL \& METHODS}

This was retrospective observational study. It was conducted in Pathology department of Pakistan Institute of Medical Sciences, Islamabad. The tests were advised by doctors of eight departments of the hospital. The test reports from 1-12- 2016 to 28-2 -2017 were included in the study. Analysis was done regarding interpretation OD the abnormal values of TSH, T2 and T4. The tests were done on automated immunoassay analyzer AIA 360 which works on the principle of flour immunoassay. The normal values used in the study were, T3 $=0.6-1.6 \mathrm{ng} / \mathrm{ml}$, T4 $=4-11$ $\mu \mathrm{g} / \mathrm{dl}$, and $\mathrm{TSH}=0.25-5.25 \mu \mathrm{lU} / \mathrm{mL}$. The data regarding the number of entitled patients and the cost of each of T3, T4 and TSH was determined. Also the number of cases where the thyroid profile was normal were determined and analysis was made about whether was there any need to prescribe full profile of Thyroid function tests or only TSH would have been sufficient to detect thyroid disorder.

\section{RESULTS}

1491 patients who had done thyroid function tests were analyzed in this study.

Age of the study sample ranged from 1 year to 80 years, with mean of $25 \pm 6.5$ years.

The gender distribution of the study sample is shown in Figure-1.

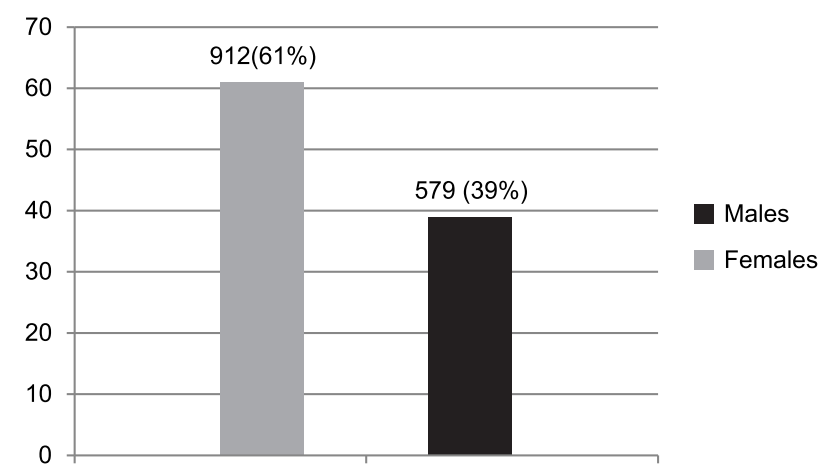

Figure-1. Gender distribution of the study population $(n=1491)$.

\begin{tabular}{|l|c|}
\hline \multicolumn{1}{|c|}{ Type of Sample } & Number of Cases n (\%) \\
\hline Entitled & $700(46.9 \%)$ \\
\hline Paid & $791(53.1 \%)$ \\
\hline
\end{tabular}

Table-I. Frequency of entitled versus paid patients $(n=1491)$.

\begin{tabular}{|l|c|}
\hline \multicolumn{1}{|c|}{ Department } & n (\%) \\
\hline Medicine & $644(43.2 \%)$ \\
\hline Gynecology and obstetrics & $549(36.8 \%)$ \\
\hline Psyciatry & $146(9.8 \%)$ \\
\hline ENT & $110(7.4 \%)$ \\
\hline Surgery & $12(0.8 \%)$ \\
\hline Dermatology & $19(1.3 \%)$ \\
\hline Paediatrics & $6(0.4 \%)$ \\
\hline Orthopedics & $5(0.3 \%)$ \\
\hline $\begin{array}{r}\text { Table-II. Pattern of samples as collected from } \\
\text { different departments of Pakistan Institute Medical } \\
\text { Sciences (n=1491). }\end{array}$
\end{tabular}




\begin{tabular}{|l|c|c|c|c|c|}
\hline & $\begin{array}{c}\text { Normal } \\
\text { cases } \\
\text { (T3, T4, TSH } \\
\text { Normal) }\end{array}$ & $\begin{array}{c}\text { Hyperthyroidism } \\
\text { (T3, T4 } \\
\text { increased, TSH } \\
\text { decreased) }\end{array}$ & $\begin{array}{c}\text { Hypothyroidism } \\
\text { (T3, T4 } \\
\text { decreased , TSH } \\
\text { increased) }\end{array}$ & $\begin{array}{c}\text { Sub clinical } \\
\text { hyper thyroidism } \\
\text { (T3, T4 normal, } \\
\text { TSH decreased) }\end{array}$ & $\begin{array}{c}\text { Subclinical } \\
\text { hypothyroidism } \\
\text { (T3, T4 normal, } \\
\text { TSH increased) }\end{array}$ \\
\hline Number of cases $\mathrm{n}(\%)$ & $838(56.2 \%)$ & $450(30 \%)$ & $170(10.1 \%)$ & $28(1.8 \%)$ & $5(0.3 \%)$ \\
\hline
\end{tabular}

Table-III. Pattern of results of thyroid function tests in 1491 study subjects.

\begin{tabular}{|l|c|}
\hline \multicolumn{1}{|c|}{ Name of the Test } & Pakistani Rupees \\
\hline T3 & $500 /-$ \\
\hline T4 & $500 /-$ \\
\hline TSH & $500 /-$ \\
\hline
\end{tabular}

Table-IV. Cost of T3, T4, and TSH in the laboratory.

\section{DISCUSSION}

In our study, mean age of the study population was 25 years. It means most of the cases were of the younger age group. About 912 (61\%) cases were females. It means that most of the cases presenting with the symptoms of thyroid disorders were females.

In our study, out of 1491 cases, about 700 (46.9\%) patients were entitled. So, in these cases, the tests were done for free and no money was taken from them. The cost of these patients is from the government funds. It means that almost in half the cases, the government has to afford the expenses of the tests performed. It suggests that if thyroid function tests are not performed judiciously and wisely, this will put an extra financial burden on hospital finance and the fund which could have been used in a more apt place is wasted here.

In our study, we found that the maximum number of tests were prescribed from medicine department, followed by Gynecology and obstetrics, Psychiatry and ENT. So, the awareness should be given to the doctors and junior doctors of these departments. Focus should be made on these departments to educate the junior docs to advise TFTS not as a whole profile but as specific TSH. ${ }^{1}$ This is so because $\mathrm{T}$ is the junior doctors that are prescribing most of the thyroid function tests. ${ }^{1}$ If TSH is abnormal, further T3 and T4 can be advised later. This way, the cost of T3 and T4 paid by the Hospital in case of entitled patients will be saved. These funds can be diverted to other areas of the hospitals.

We found that in more than half of the cases where thyroid function tests were performed, the reports were normal. So, advising the T3 and T4 in these cases was a financial burden on poor patients and hospital fund in cases of entitled patients. It would have been more smart to use isolated TSH initially, and if it was normal, no further tests would be necessary. This would save the patient from additional financial burden. Also, the literature suggests that TSH levels are the first to change in thyroid disorders, even in cases of subclinical hypo and hyper thyroid conditions. ${ }^{1}$ The literature suggests that the increased number of thyroid function tests being done is much more than the actual prevalence of thyroid patients. ${ }^{1}$ It means that a lot of patients having normal thyroid also do thyroid function tests. It is suggested that the physicians should advise thyroid function tests wisely in order to avoid additional financial burden on patients as well as on the government. ${ }^{1,8}$

When prices of the T3, T4 and TSH were assessed, it was found that hospital charges 500 Pakistani rupees each test. So, a thyroid profile with T3, T4 and TSH collectively costs about $1500 /-$ Pakistani rupees. If the whole profile is advised to every patient injudiciously, knowing that majority of the cases have normal thyroid profile $\mathrm{m}$ and majority of the cases are entitled, it will put a big financial burden on patients and also on the hospital finances. According to a met analysis done by Zhelev, the British government is spending 30 million pounds per year on thyroid function tests. ${ }^{1}$ This is a big burden on their economy. ${ }^{1}$ This aspect needs to be explained to the junior doctors working in the hospital so that they may be aware while advising thyroid function tests. They should be enlightened that initially, isolated TSH should be advised which 
costs 500/- rupees only. If, the TSH is abnormal, it should be followed by the T3 and T4. This way, the patients will not be overburdened nor the hospital finances. Literature also suggests that there should be appropriate requests for thyroid functions and the test should not be done where not required. ${ }^{1,8}$

There is no benefits of ordering whole panel of Thyroid function tests as compared to isolated $\mathrm{TSH}$. There is a need to develop a scheme in order to decrease the economical burden of these tests on the patients. There are measures taken worldwide to ensure appropriate use of thyroid functions, and there has been variable outcomes of these efforts. ${ }^{9-16}$

\section{CONCLUSION}

Performing whole panel of the thyroid function tests instead of isolated TSH puts a huge financial burden on patients as well on the hospital finances. There is a need to spread awareness among junior doctors to ensure judicious advising of the thyroid function tests in patients especially in cases coming from low socioeconomic class and in cases of entitled patients, whose burden is from the government funds. This holds true in developing countries like Pakistan. The fund thus saved can be diverted to other areas of health services.

\section{Acknowledgement:}

All glories be to almighty Allah for helping me complete the manuscript.

\section{Copyright(C) 13 Apr, 2020.}

\section{REFERENCES}

1. Zhelev Z, Abbott R, Rogers M, Fleming S, Patterson A, Hamilton WT, Heaton J, Coon JT, Vaidya B, Hyde C. Effectiveness of interventions to reduce ordering of thyroid function tests: a systematic review. BMJ open. 2016 Jun 1;6(6).

2. Madariaga AG, Palacios SS, Grima FG. The incidence and prevalence of thyroid dysfunction in Europe: $A$ meta-analysis. J Clin Endocrinol Metab. 2014; 99:92331.
3. Chair R, Burch HB, Cooper DS. Hyperthyroidism and other causes of thyrotoxicosis: Management guidelines of the American Thyroid Association and American Association of Clinical Endocrinologists. Thyroid 2011; 21:593-646.

4. Bayram $\mathrm{C}$, Valenti $\mathrm{L}$, Britt $\mathrm{H}$. Orders for thyroid function tests- changes over 10 years. Aust Fam Physician 2012; 41:555.

5. Leese GP, Flynn RV, Jung RT. Increasing prevalence and incidence of thyroid disease in Tayside, Scotland: The Thyroid Epidemiology Audit and Research Study (TEARS). Clin Endocrinol (Oxf). 2008; 68:311-16

6. Thomas RE, Croal BL, Ramsay C. Effect of enhanced feedback and brief educational reminder messages on laboratory test requesting in primary care: $A$ cluster randomised trial. Lancet 2006; 367:1990-6.

7. Horn DM, Koplan KE, Senese MD. The impact of cost displays on primary care physician laboratory test ordering. J Gen Intern Med. 2014; 29:708-14.

8. Taylor PN, Iqbal A, Minassian C. Falling threshold for treatment of borderline elevated thyrotropin levelsbalancing benefits and risks: Evidence from a large community-based study. JAMA Intern Med. 2014; 174:32-9.

9. Solomon DH, Hashimoto H, Daltroy L. Techniques to improve physicians' use of diagnostic tests: A new conceptual framework. JAMA 1998; 280:2020-7.

10. Eisenberg JM. Physician utilization: The state of research about physicians' practice patterns. Med Care 2002; 40:1016-35.

11. Grossman RM. A review of physician costcontainment strategies for laboratory testing. Med Care 1983; 21:783-802.

12. Oxman AD, Thomson MA, Davis DA. No magic bullets: A systematic review of 102 trials of interventions to improve professional practice. CMAJ 1995; 153:142331.

13. Young DW. Improving laboratory usage: A review. Postgrad Med J .1988; 64:283-9.

14. Berwick DM, Coltin KL. Feedback reduces test use in a health maintenance organization. JAMA 1986; 255:1450-4.

15. Gama R, Nightingale PG, Broughton PM. Feedback of laboratory usage and cost data to clinicians: Does it alter requesting behavior? Ann Clin Biochem 1991; 28(Pt 2):143-9. 
16. Cipullo JA, Mostoufizadeh M. Bringing order to test orders: One lab's story. CAP Today 1996; 10:20-2.

\section{AUTHORSHIP AND CONTRIBUTION DECLARATION}

\begin{tabular}{|c|c|c|c|}
\hline Sr. \# & Author(s) Full Name & Contribution to the paper & Author(s) Signature \\
\hline 1 & Saman Waqar & Principal author, Critical review. & So \\
\hline 2 & M. Ihtesham Khan & $\begin{array}{l}\text { Write up, Discussion, Result } \\
\text { compilation. }\end{array}$ & \\
\hline 3 & Rahy Farooq & Data collection. & \\
\hline 4 & Mahira Mobeen & Data analysis. & 6 \\
\hline 5 & Rafi Raza Ahmad & Literature review. & \\
\hline
\end{tabular}

